\title{
Rancang Bangun Perangkat Rekam Medik Berbasis Teknologi RFID
}

\author{
(Hospital Medical Record Tools Based RFID Technology)
}

\author{
Linda Atmawati Wulandaru, Bambang Supeno, S.T., M.T., Sumardi, S.T., M.T. \\ Jurusan Teknik Elektro, Fakultas Teknik, Universitas Jember (UNEJ) \\ Jln. Kalimantan 37, Jember 68121 \\ E-mail:piyeplinda@gmail.com
}

\begin{abstract}
Abstrak
Penerapan aplikasi teknologi RFID (Radio Frequency Identification) di rumah sakit Indonesia relatif baru dibandingkan dengan sektor lainnya seperti instansi manufaktur, retail, perpustakaan, logistik, pendidikan dan pemerintah. Banyak para akademisi dan praktisi dibidang teknologi yang meyakini bahwa teknologi RFID memiliki potensi yang sangat besar untuk memberikan manfaat bagi rumah sakit yang ada dinegara berkembang seperti di Indonesia. Penerapan perangkat rekam medik berbasis teknologi RFID diinstansi kesehatan diharapkan dapat mempermudah dokter dalam melakukan pelayanan kesehatan terhadap pasien. Berdasarkan pentingnya peranan data rekam medis diinstansi kesehatan seperti di rumah sakit maka dirancanglah suatu prototype perangkat rekam medis berbasis teknologi RFID. Dalam perancangan dan pembuatan perangkat rekam medik berbasis teknologi RFID menggunakan RFID reader jenis Mifare RC522 dan sebuah Tag RFID jenis Mifare S50 klasik yang terhubung dengan LCD 16x2 dan sebuah mikrokontrol Arduino Uno sebagai pusat kontrol utama dari perangkat. Sedangkan dalam pembuatan aplikasi perangkat rekam medik berbasis teknologi RFID menggunakan pemograman Visual basic dan database desktop Microsoft Acces.
\end{abstract}

Kata Kunci: Arduino UNO, LCD 16x2, Visual Basic, Microsoft Acces, RFID Mifare RC522.

\section{Abstract}

Implementation of the application of RFID technology (Radio Frequency Identification) in hospital in Indonesia is relatively new compared to other sectors such as manufacturing establishments, retail, library, logistics, education and government. Many academics and practitioners in the field of technology who believe that RFID technology has a huge potential to provide benefits for hospitals in developing countries such as Indonesia. Implementation of the RFID technology-based medical records in health institutions expected to facilitate doctors in the health service to patients. Based on the importance of the role of medical records such as in hospitals then designed some medical records prototype device use RFID technology. In the design and manufacture of medical records prototype device use RFID technology using RFID Mifare RFID reader RC522 and Mifare S50 RFID Tag classic that connected to LCD and an Arduino Uno Mikrokontrol as the main control center of the device. Meanwhile, in the manufacture of medical record device applications using RFID technology based programming Visual Basic and Microsoft Access desktop database.

Keywords: Arduino UNO, LCD 16x2, Visual Basic, Microsoft Acces, RFID Mifare RC522.

\section{PENDAHULUAN}

Penerapan aplikasi teknologi RFID (Radio Frequency Identification) di Rumah Sakit Indonesia relatif baru dibandingkan dengan sektor lainnya seperti manufaktur, retail, perpustakaan, logistik dan instansi pendidikan serta instansi pemerintah. Banyak para akademisi dan praktisi di bidang teknologi yang meyakini bahwa teknologi RFID memiliki potensi sangat besar untuk memberikan manfaat bagi rumah sakit yang ada di negara berkembang seperti di Indonesia [1].

Di Negara maju seperti Amerika Serikat dan Eropa, alasan utama dari pengadopsian teknologi RFID adalah untuk meningkatkan daya saing bisnis dengan melakukan peningkatan keselamatan pasien. Kontras dengan kondisi di Indonesia, pengadopsian dari teknologi RFID di rumah sakit sebagai perangkat rekam medis hampir belum ada yang menggunakan, padahal penyebaran yang cepat dan dramatis dari beberapa penyakit telah meningkat pada tahun-tahun terakhir ini seperti penyakit AIDS/HIV, demam berdarah, flu mempengaruhi Indonesia diikuti dengan banyaknya penderita yang meninggal [2]. Beberapa rumah sakit di Indonesia telah berusaha mencegah kemungkinan penyebaran tanpa bantuan teknologi seperti teknologi RFID. Padahal adanya keberhasilan implementasikan teknologi RFID di rumah sakit Taiwan dan Singapura untuk mereduksi penyebaran pademi ternyata tidak diikuti oleh rumah sakit di Indonesia. Hal ini menunjukkan bahwa terjadi hambatan dalam pengadopsian teknologi RFID sebagai perangkat rekam medik di rumah sakit Indonesia. Berdasarkan latar belakang pentingnya peranan data rekam medis di instansi kesehatan seperti di rumah sakit maka pada penelitian skripsi ini akan dibuat suatu perangkat rekam medis yang dapat menyimpan dan membaca data identitas para pasien beserta riwayat kesehatannya.

Data kesehatan tersebut disimpan di dalam databese sistem dan data tersebut terintegrasi dengan suatu chip RFID ( Tag RFID), sehingga data tersebut secara fleksibel 
dapat di akses oleh user (dokter) pada saat pasien pergi berobat ke suatu instansi kesehatan. Ketika pasien berobat ke dokter, dokter dapat melihat riwayat kesehatan subjek (pasien) dengan membaca hasil scaning identifikasi Tag RFID yang dibawa oleh (pasien) melalui reader RFID yang selanjutnya data riwayat rekam medis pasien kemudian akan ditampilkan melalui perangkat komputer ke dokter yang sedang bertugas [3].

\section{TINJAUAN PUSTAKA}

\subsection{Pengertian RFID}

RFID adalah singkatan dari ( Radio Frequency Identification ) adalah sistem identifikasi tanpa kabel yang memungkinkan pengambilan data tanpa harus bersentuhan seperti barcode dan magnetic card. RFID kini banyak dipakai diberbagai bidang seperti perusahaan, supermarket, rumah sakit bahkan terakhir digunakan dimobil untuk identifikasi penggunaan BBM bersubsidi. Teknologi RFID menggunakan sistem identifikasi frekuensi gelombang radio (Wahyu Adam, 2014).

\subsection{RFID Reader Mifare RC522}

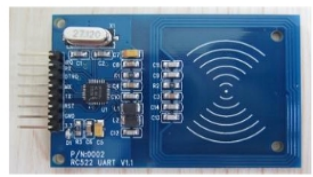

(Gambar 2.1 Gambar RFID Reader Mifare RC522)

RFID reader Mifare RC522 merupakan suatu modul RFID reader yang memiliki high frequency module (transmitter dan receiver), control module dan juga coupling element (coil dan microwave antenna) yang berfungsi membangkitkan sinyal frekunsi radio untuk mengaktifkan RFID tag. RFID reader Mifare RC522 mendukung sistem komunikasi data $\mathrm{I}^{2} \mathrm{C}$ bus interface, SPI (Serial Peripal Interface) dan serial UART (Universal Syncronous Asyncronous Receiver Trasmiter).

Mendukung jenis card RFID tag jenis MF1XX20, MF1XXS70 dan MF1XXS50 dengan jarak pembacaan kurang dari $10 \mathrm{~cm}$. Ketika sebuah RFID tag melewati sinyal frekuensi radio pada RFID reader, maka RFID reader tersebut akan mendeteksi keberadaan RFID tag, selanjutnya RFID tag akan mengirimkan sinyal balik untuk pemrosesan data yang telah tersimpan dalam memori tag sebagai respon ( http://elektronika - dasar. 12 Oktober 2015 : 22.30 wib).

\subsection{Tag RFID Mifare S50}

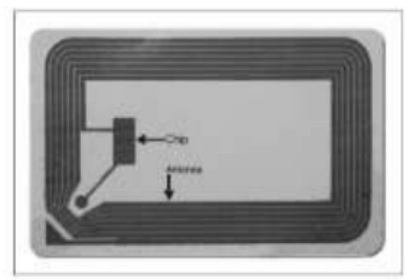

(Gambar 2.2 Tag RFID Mifare S50)

Chips berukuran sekecil butiran pasir, seukuran $0.4 \mathrm{~mm}$ Chips tersebut menyimpan nomor seri yang unik atau informasi lainnya tergantung kepada tipe memorinya. Tipe memori itu sendiri dapat read-only, read-write atau write on ceread-many. Antena yang terpasang pada chips mengirimkan informasi dari chips ke reader. Biasanya rentang pembacaan diindikasikan dengan besarnya antena. Antena yang lebih besar mengindikasikan rentang pembacaan yang lebih jauh. Tag tersebut terpasang atau tertanam dalam obyek yang akan diidentifikasi. Tag dapat discan dengan reader bergerak maupun stasioner menggunakan gelombang radio (http://elektronika - dasar. 12 Oktober $2015: 22.30 \mathrm{wib}$ )

\subsection{Mikrokontrol Arduino Uno R3}

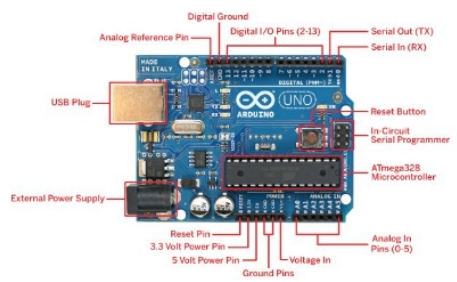

(Gambar 2.3 Mikrokontrol Arduino Uno)

Arduino Uno adalah board mikrokontroler berbasis ATmega328. Uno memiliki 14 pin digital input / output (dimana 6 dapat digunakan sebagai output PWM), 6 input analog, resonator keramik $16 \mathrm{MHz}$, koneksi USB, jack listrik, header ICSP, dan tombol reset.

Arduino Uno dibangun berdasarkan apa yang diperlukan untuk mendukung untuk pemograman mikrokontroler, sumber daya bisa menggunakan power USB (jika terhubung ke komputer dengan kabel USB) dan juga dengan adaptor atau baterai. Arduino Uno berbeda dari semua papan sebelumnya dalam hal tidak menggunakan FTDI chip driver USB-to-serial. Sebaliknya, fitur Atmega16U2 (Atmega8U2 sampai versi R2) diprogram sebagai konverter USB-to-serial.

Revisi 2 dari Uno memiliki resistor pulling 8U2 HWB yang terhubung ke tanah, sehingga lebih mudah untuk menggunakan mode DFU. Arduino memiliki sejumlah fasilitas untuk berkomunikasi dengan komputer. Adapun beberapa fasilitas yang tersedia pada Arduino terdapat mikrokontrol ATmega328 menyediakan komunikasi UART TTL (5V) untuk komunikasi serial, yang tersedia di pin digital 0 (RX) dan 1 (TX). (http://elektronika - dasar. 12 Oktober $2015: 22.30$ wib )

\subsection{LCD 16x2}

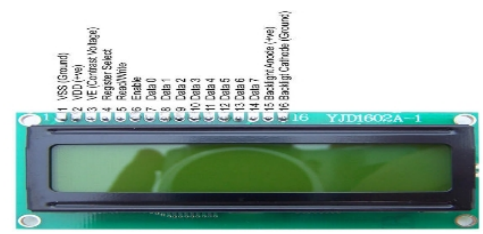

(Gambar 2.4 LCD karakter 16x2)

LCD adalah singkatan dari kata liquid crystal display, yaitu panel penampil yang dibuat dari bahan kristal cair. Kristal dengan sifat - sifat khusus yang menampilkan warna lengkap yang berasal dari efek pantulan atau transmisi cahaya dengan panjang gelombang pada sudut tertentu, merupakan salah satu rekayaan penting yang menunjang kebutuhan akan peralatan elektronik serba tipis 
dan ringan (Saludin Muis, 2013).

\subsection{Microsoft Visual Basic 2012}

Microsoft Visual Basic digunakan sebagai perangkat lunak untuk pembuatan program dengan aplikasi GUI (Graphical User Interface) atau program yang memungkinkan pengguna komputer dapat berkomunikasi menggunakan media grafik atau gambar dengan komputer tersebut. Microsoft Visual Basic menyediakan fasilitas yang memungkinkan untuk menyusun sebuah program dengan memasang objek-objek tertentu dalam sebuah form.

Pemrograman Microsoft Visual Basic dapat di hubungkan dengan suatu perangkat keras yang berhubungan menggunakan serial port, contohnya adalah digunakan untuk aplikasi RFID, agar data RFID dapat diterima oleh program aplikasi digunakan suatu komponen dari Microsoft Visual Basic itu sendiri yaitu MS Comm, komponen MS Comm berfungsi untuk mengadakan hubungan dengan serial port PC, berhubungan antara alat komunikasi lain (contohnya RFID), Memonitor dan merespon event dan error yang terjadi pada hubungan serial dan memonitoring pertukaran data. (Winarsi,Eka.dkk.Sistem parkir otomatis berbasis teknologi RFID. Fakultas Teknologi Industri Universitas Trisakti.2015.vol :8;2,16)

\section{METODE PENELITIAN}

Penelitian implementasi dari "Rancang Bangun Perangkat Rekam Medik Berbasis Teknologi RFID“ dilaksanakan di dua tempat yakni labolatorium Elektronika Terapan Jurusan Teknik Elektro, Fakultas Teknik Universitas Jember yang beralamatkam di jalan Slamet Riyadi No. 62 Patrang Jember dan instansi kesehatan Unej Medical Center (UMC) yang beralamatkan di jalan Kalimantan 1 No 37 Kampus Tegal Boto Jember mulai bulan Januari- Juni 2016

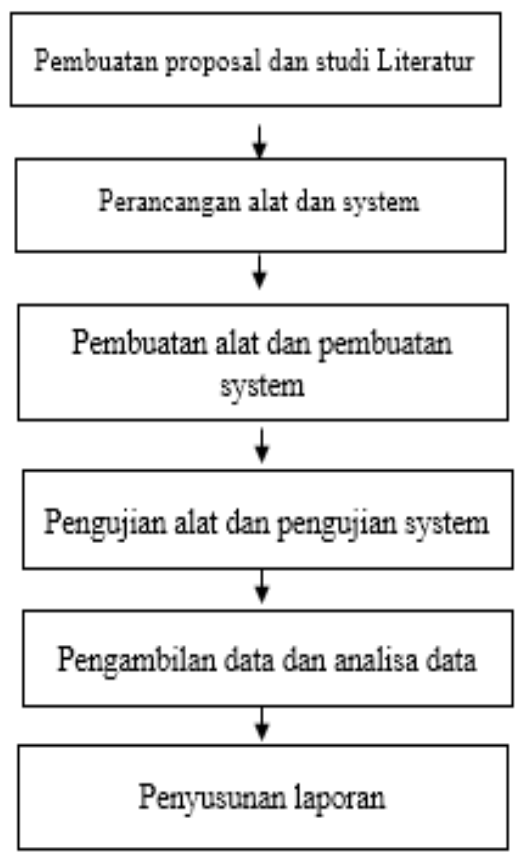

Gambar 3.1 Diagram Flowchart Penelitian

\subsection{Desain Perangkat Keras (Hadware)}

Pada blok diagram perangkat rekam medik berbasis teknologi RFID dapat di ilustrasikan pada gambar 3.2. Pada diagram blok di atas control utama perangkat reka medis berbasis teknologi RFID terletak pada system minimum mikrokontrol Arduino Uno. Dimana prinsip kerja dari perangkat yaitu ketika mikrokontrol arduino uno mendapatkan supply tegangan dari personal computer sebesar 7-12 volt maka daya yang di terima oleh mikrokontrol akan di alirkan RFID reader sebesar 3.3 volt DC.

Ketika sudah mendapatkan suplly tegangan dari sistem minimum mikrokontrol arduino Uno R3 maka RFID reader akan mengeluarkan frekuensi gelombang radio sebesar 13.56 Mhz yang di gunakan oleh reader untuk mengidentifikasi keberadaan tag RFID, jika keberadaan tag sudah terdeteksi oleh reader selanjutnya tag akan mengirimkan kembali pantulan gelombang radio kepada reader di mana pantulan gelombanng radio yang di kirimkan tag kepada reader menyimpan sejumlah informasi berupa kode tertentu Selanjutnya informasi di terima oleh reader akan di proses oleh mikrokontrol untuk menampilkan ID pasien pada LCD dan catatan rekam medis pasien di personal komputer.

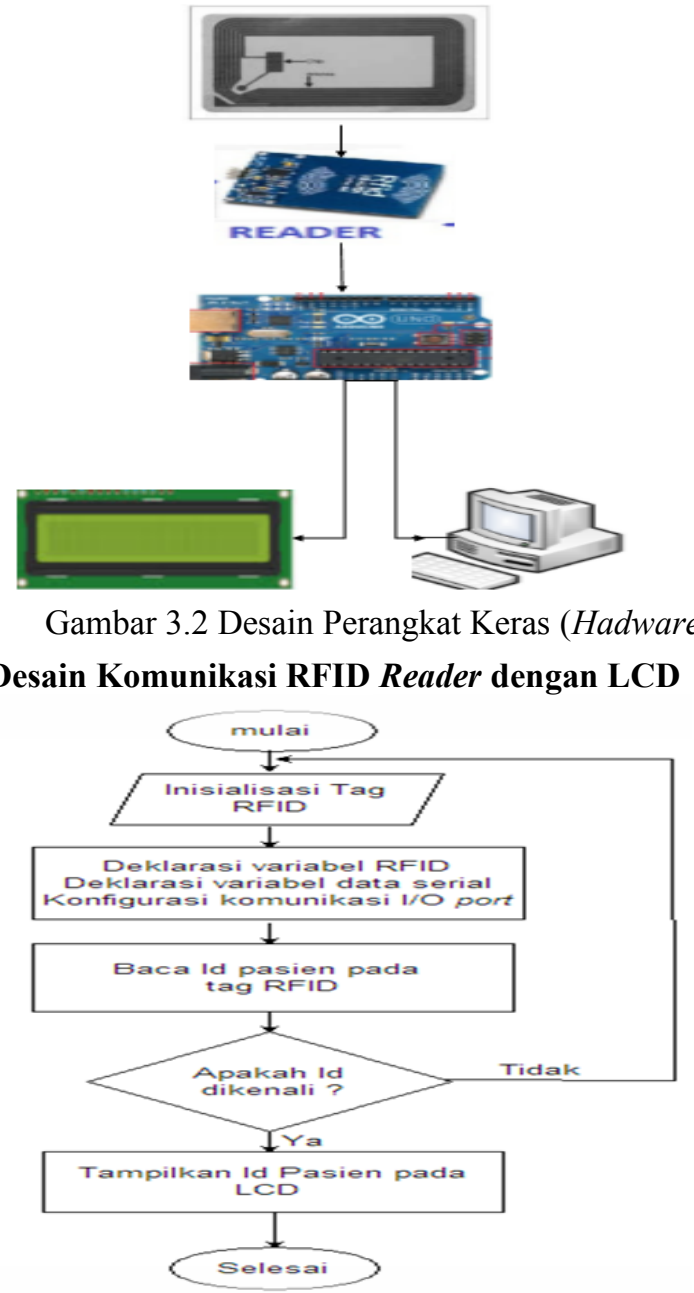

Gambar 3.3 Desain Komunkasi RFID Reader dengan LCD 


\section{Penjelasan Flowchart}

1. Langkah pertama yaitu insialisasi komunikasi dengan baudrate UART $=9600 \mathrm{bps}$ dan melakukan konfigurasi I/O port yang di gunakan untuk melakukan deklarasi variabel yang akan di gunakan

2. Agar perangkat rekam medik berbasis teknologi RFID berjalan dengan baik yakni pertama - tama menginisalisasi RFID tag pada program pada program yang akan di buat.

3. Selanjutnya setelah selesai menginisialisasi RFID tag selanjutkan mendeklarasikan variabel RFID, variabel data serial dan mengkonfigurasi komunikasi pada I/O port. Setelah semua variabel yang di butuhkan dalam pembuatan program komunikasi antara mikrokontrol Arduino Uno, RFID reader dan LCD sudah selesai di deklarasikan langkah selanjutnya yakni pembacaan Id pasien oleh RFID reader jika Id di kenali maka Id pasien akan di tampilkan di LCD namun jika Id pasien tidak dikenali oleh reader maka akan melakukan perintah looping untuk inisialiasi Id pasien yang baru.

\subsection{Desain Konfigurasi pin Arduino dengan LCD 16x2}

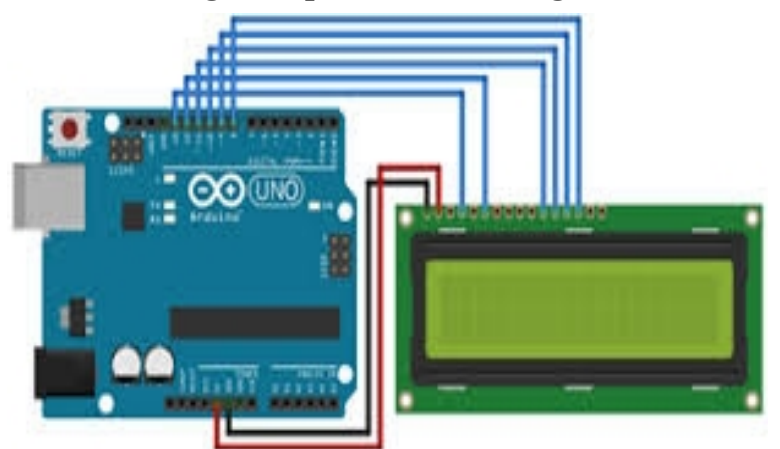

Gambar 3.4 Desain Komunkasi pin Arduino dengan LCD $16 \times 2$

Desain konfigurasi pin Arduino dengan LCD karakter $16 \times 2$ terlihat pada gambar 3.4 di mana komunikasi serial antara mikrokontrol Arduino Uno dengan LCD karakter 16×2 menggunakan sistem komunikasi UART. Adapun konfigurasi pin mikrokrol Arduino Uno dengan LCD 16x2 yakni sebagai berikut ini :
a) Pin 8
: pin RS
b) Pin 7
: pin Enable LCD
c) Pin 6
: pin D4
d) Pin 5
: pin D5
e) Pin 4
: pin D6
f) Pin 3
: pin D7
g) Ground
: pin Rw
h) Vec 5 Volt : pin RD dengan hambatan 10K ohm

\section{Konfigurasi pin Arduino dengan RFID Reader :}

Desain konfigurasi pin Arduino dengan LCD karakter $16 \times 2$ terlihat pada gambar 3.5 di mana komunikasi serial antara mikrokontrol Arduino Uno dengan RFID reader menggunakan sistem komunikasi SPI (Serial Peripal Interface). RFID reader akan bekerja ketika mendapatkan suply tegangan dari mikrokontrol Aeduino uno sebesar 3.3 Volt DC. Adapun konfigurasi pin Arduno Uno dengan RFID reader yakni sebagai berikut:
a) Vec 3.3 volt : pin 3.3 volt RFID reader
b) Ground : : pin ground RFID reader
c) Pin $9 \quad$ : pin reset RFID reader
d) Pin $10 \quad$ : pin ss RFID reader

e) Pin $11 \quad$ : pin Mosi RFID reader

f) Pin 12 : pin Miso RFID reader

\subsection{Desain Flowchart Sistem Secara Keseluruhan :}
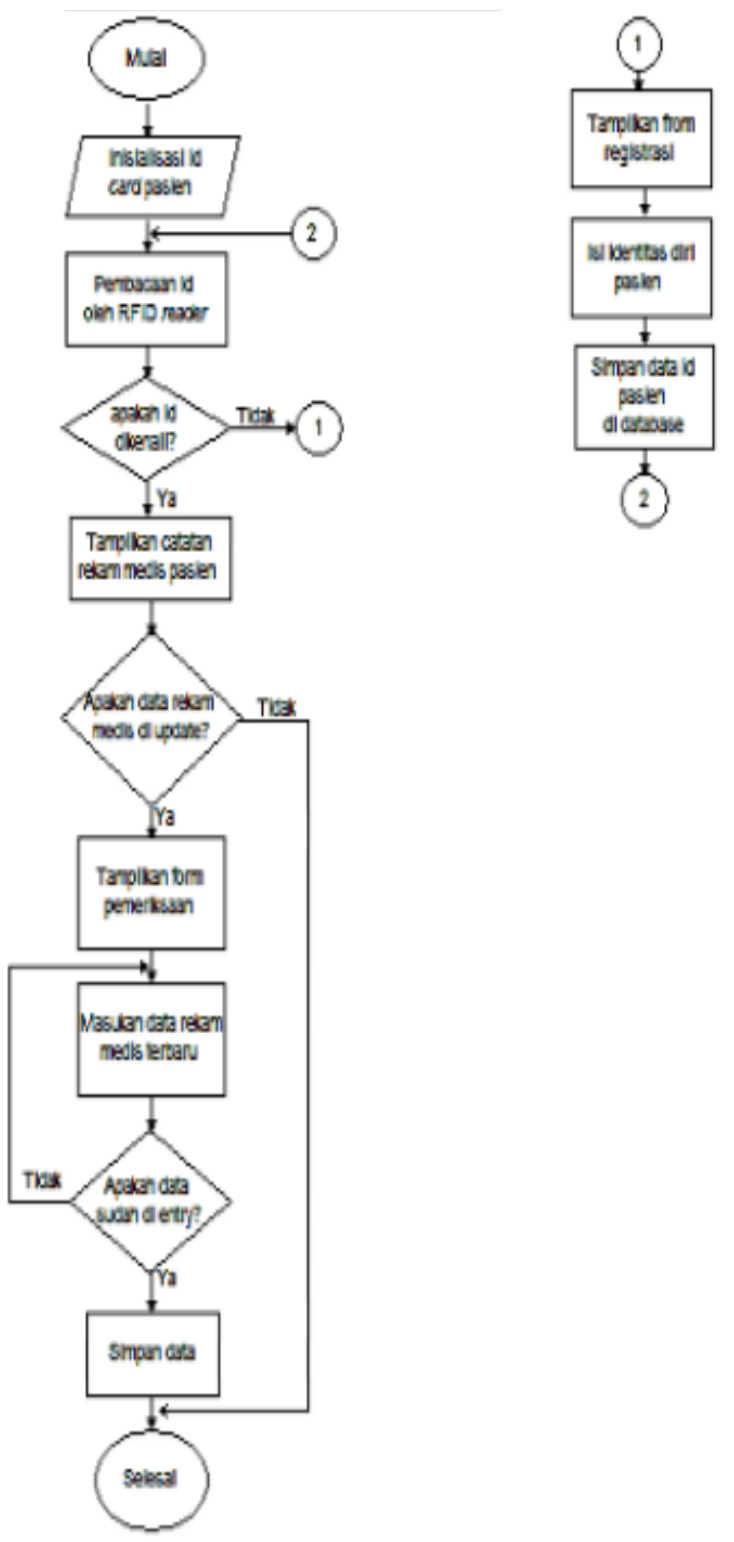

Gambar 3.5 Desain Flowchat Secara Keseluruhan

\section{Penjelasan Flowchart :}

1. Langkah pertama yakni inisialisasi Id pasien

2. Selanjutnya pembacaan Id pasien oleh RFID reader

3. Saat Id pasien di kenali maka catatan rekam medis yang telah lalu akan Catatan rekam medis pasien yang telah lalu akan di tampilkan di layak komputer, namun jika Id pasien tidak di kenali maka akan di tampilkan form registrasi untuk membuat Id pasien baru beserta data diri pasien 4. Selenjutnya setelah selesai mengidentifikasi diri pasien selanjutnya aplikasi akan tampil perintah apakah data rekam medis pasien akan di perbarui atau tidak.

5. Jika data rekam medis akan di perbaharui maka dokter tinggal mengklik Id pasien untuk mengisikan data rekam medis yang terbaru di form pemeriksaan jika data rekam medis sudah di perbaharui maka catatan rekam medis pasien dapat langsung disimpan didatabase Microsoft Acces 6. Selesai 


\section{HASIL PENELITIAN}

Setelah melakukan perancangan dan pembuatan perangkat rekam berbasis RFID selesai di lakukan. Proses selanjutnya yaitu melakukan pengujian terhadap perancangan sistem perangkat rekam medis berbasis teknlogi perbagian meliputi hadware dan sofware serta pengujian alat secara keseluruhan perlu dilakukan guna mengetahui kinerja dan kelayakan alat untuk bisa digunakan atau tidak .

\subsection{Pengujian Perangkat Keras (Hadware)}

Dalam pengujian perangkat keras meliputi 3 parameter pengujian diantaranya yaitu :

\subsubsection{Pengujian Sensor RFID Reader Berdasarkan Parameter Jarak}

4.1 Data pengujian berdasarkan paramater jarak

\begin{tabular}{ccrc}
\hline No & Jarak & Tag 1 & Tag 2 \\
\hline $\mathbf{1}$ & $1 \mathrm{~cm}$ & $\sqrt{ }$ & $\sqrt{ }$ \\
\hline $\mathbf{2}$ & $2 \mathrm{~cm}$ & $\sqrt{ }$ & $\sqrt{ }$ \\
\hline $\mathbf{3}$ & $3 \mathrm{~cm}$ & $\sqrt{ }$ & $\sqrt{ }$ \\
\hline $\mathbf{4}$ & $4 \mathrm{~cm}$ & $\sqrt{ }$ & $\sqrt{ }$ \\
\hline $\mathbf{5}$ & $5 \mathrm{~cm}$ & $\sqrt{ }$ & $\sqrt{ }$ \\
\hline $\mathbf{6}$ & $6 \mathrm{~cm}$ & $\sqrt{ }$ & $\sqrt{ }$ \\
\hline $\mathbf{7}$ & $7 \mathrm{~cm}$ & $\sqrt{ }$ \\
\hline $\mathbf{8}$ & $8 \mathrm{~cm}$ & $\sqrt{ }$ & $\mathrm{X}$ \\
\hline $\mathbf{9}$ & $9 \mathrm{~cm}$ & $\mathrm{x}$ & \\
\hline $\mathbf{1 0}$ & $10 \mathrm{~cm}$ & $\mathrm{x}$ & \\
\hline
\end{tabular}

Keterangan :

$\sqrt{ }$ : Tag sukses diidentikasi oleh RFID reader

$\mathrm{X}$ : Tag gagal diidentikasi oleh RFID reader

Pengujian perangkat keras yang pertama kali dilakukan yaitu pengujian rangkaian sensor RFID reader Mifare RC522 berdasarkan parameter jarak. Pada pengujian yang pertama menggunakan RFID Tag jenis Mifare RC522 S50 klasik sejumlah 8 Tag. Berdasarkan keterangan datasheet sensor RFID reader Mifare RC522 mendukung pembacaan RFID Tag Mifare jenis S50 klasik.

Adapun sensor RFID reader Mifare RC522 bekerja pada frekuensi sedang dengan panjang gelombang radio sebesar 13.56 Mhz dengan kecepatan baca sedang serta jangkauan jarak pembacaan maksimal yakni sebesar $10 \mathrm{~cm}$. Berdasarkan data hasil pengujian sensor RFID reader pada table 4.1 dapat diketahui bahwa ketika RFID Tag berada pada rentan jarak 1 sampai $8 \mathrm{~cm}$ dari sensor RFID reader proses pembacaan data serial pad RFID Tag suskses terbaca, ketika RFID Tag berada pada jarak lebih dari $8 \mathrm{~cm}$ dari RFID reader proses pembacaan RFID Tag oleh RFID reader gagal dan tidak dapat terbaca.

Proses kegagalan pembacaan kode RFID Tag oleh RFID reader disebabkan beberapa faktor seperti adanya benda penghalang akrilik setebal $3 \mathrm{~mm}$ yang menutupi proses pengiriman gelombang frekuensi radio dari RFID reader terhadap Tag sehingga menyebabkan semakin berkurangnya frekuensi gelombang radio yang di pancarkan oleh RFID reader terhadap RFID Tag

4.1.2 Pengujian Sensor RFID Reader Berdasarkan Parameter Waktu

4.2 Data pengujian berdasarkan paramater waktu

\begin{tabular}{ccccc}
\hline No & Id Pasien & Jarak & $\begin{array}{c}\text { Waktu } \\
\text { (sekon) }\end{array}$ & ket \\
\hline 1 & 41593822 & $1 \mathrm{~cm}$ & 1 & $\sqrt{ }$ \\
\cline { 3 - 5 } & & $2 \mathrm{~cm}$ & 1.13 & $\sqrt{ }$ \\
\hline & $3 \mathrm{~cm}$ & 1.14 & $\sqrt{ }$ \\
\hline & $4 \mathrm{~cm}$ & 1.14 & $\sqrt{ }$ \\
\hline & $5 \mathrm{~cm}$ & 1.14 & $\sqrt{ }$ \\
\hline & $6 \mathrm{~cm}$ & 1.23 & $\sqrt{ }$ \\
\hline & $7 \mathrm{~cm}$ & 1.25 & $\sqrt{ }$ \\
\hline & $8 \mathrm{~cm}$ & 2 & $\sqrt{ }$ \\
\hline & $9 \mathrm{~cm}$ & $\mathrm{x}$ & $\mathrm{x}$ \\
\hline & $10 \mathrm{~cm}$ & $\mathrm{x}$ & $\mathrm{X}$ \\
\hline
\end{tabular}

Keterangan :

$\downarrow$ : Tag sukses diidentikasi oleh RFID reader

$\mathrm{X}$ : Tag gagal diidentikasi oleh RFID reader

Pada pengujian yang ke dua yaitu pengujian rangkaian sensor RFID reader berdasarkan parameter waktu. Pada pengujian yang kedua ini menggunakan 8 buah RFID Tag yang sama yaitu jenis Mifare S50 klasik. Adapun pengujian yang ke dua ini bertujuan untuk mengetahui pengaruh jarak terhadap rentang waktu pembacaan data serial yang tersimpan pada RFID Tag.

Berdasarkan tabel 4.2 data hasil pengujian pengaruh jarak terhadap rentang waktu pembacaan data serial oleh sensor RFID reader yakni saat dilakukan pengujian pengaruh jarak terhadap rentang waktu pembacaan data serial RFID Tag reader yakni semakin jauh jarak tag RFID dari sensor RFID reader maka semakin lama waktu dalam pembacaan data hal ini di sebabkan karena gelombang frekuensi radio yang di pancarkan oleh RFID reader semakin berkurang dan melemah dengan seiring bertambahnya jarak pembacaan RFID Tag terhadap reader 4.1.3 Pengujian Sensor RFID reader Berdasarkan Parameter Posisi dan Sudut

4.3 Data pengujian berdasarkan paramater waktu

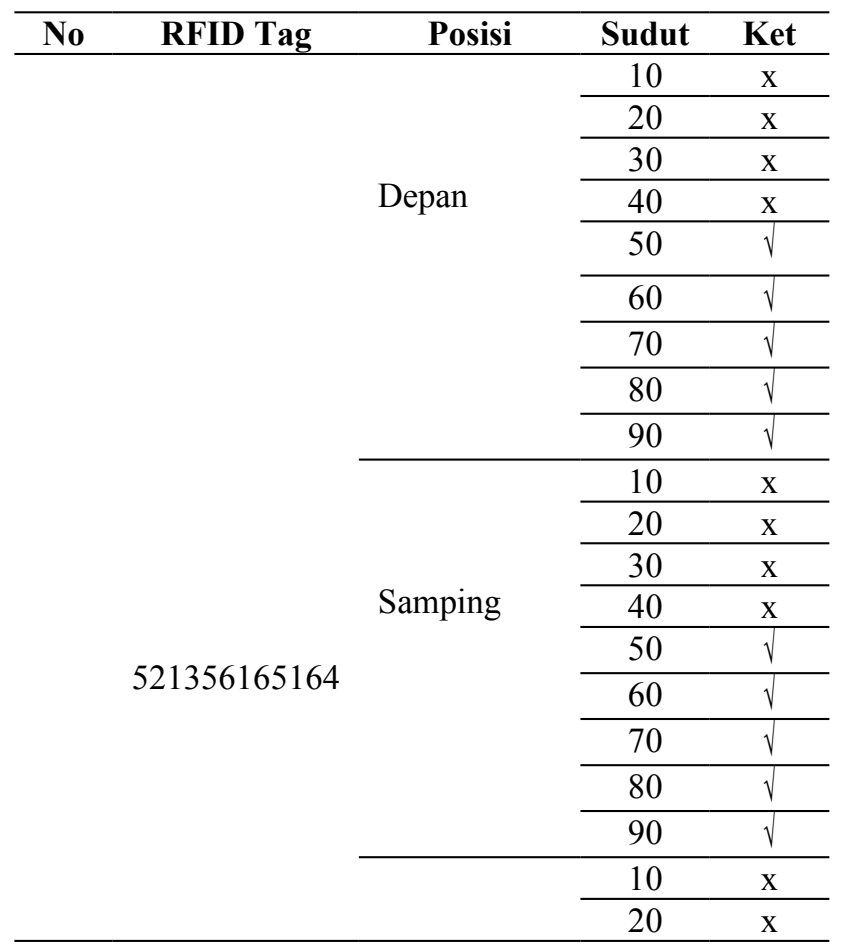




\begin{tabular}{lll}
\hline Belakang & 30 & $\mathrm{x}$ \\
\cline { 2 - 3 } & 40 & $\mathrm{x}$ \\
\cline { 2 - 3 } & 50 & $\sqrt{ }$ \\
\hline & 60 & $\sqrt{ }$ \\
\hline & 70 & $\sqrt{ }$ \\
\cline { 2 - 2 } & 80 & $\sqrt{ }$ \\
\cline { 2 - 2 } & 90 & $\sqrt{ }$ \\
\hline
\end{tabular}

Keterangan :

$\sqrt{ }$ : Tag sukses diidentikasi oleh RFID reader

$\mathrm{X}$ : Tag gagal diidentikasi oleh RFID reader

Berdasarkan data pengujian tabel 4.3 di dapatkan fakta bahwa penempatan posisi RFID Tag dan sudut RFID Tag terhadap sensor RFID reader posisi terbaik yakni di bagian depan sensor RFID reader dengan sudut peletakan $50^{\circ}$ $90^{0}$ di mana pada posisi tersebut pancaran gelombang radio frekuensi yang di pancarkan oleh sensor RFID reader terhadap RFID Tag sangat kuat

\section{Pengujian Rangkaian LCD 16x2}

4.4 Data pengujian berdasarkan paramater jarak

\begin{tabular}{lrl}
\hline No & RFID Tag & Gambar \\
\hline 1 & 521356165164 & $\begin{array}{c}\text { ID Ands } 8 \\
521356165164\end{array}$ \\
\hline & & ID And 8 \\
& 100119213138 & 100192131381 \\
\hline
\end{tabular}

Pada pengujian yang ke empat yaitu pengujian rangkaian LCD $16 \times 2$. Pengujian rangkaian LCD $16 \times 2$ dengan sensor RFID reader bertujuan untuk mengetahui komunikasi antara rangkaian LCD 16x2 dan sensor RFID reader dapat berjalan dengan baik atau tidak. Pada saat dilakukan pengujian rangkaian LCD 16×2 menggunakan 3 buah sampel RFID Tag dengan kode yang nomer berbedabeda.

Pada saat dilakukan pengujian proses pembacaan sensor RFID reader agar dapat menampilkan kode serial yang tersimpan pada masing-masing RFID Tag. Proses pengujian dilakukan secara bergantian antara satu RFID Tag dengan Tag yang lainnya. Data hasil pengujian terlihat pada tabel 4.4 dimana 3 buah RFID Tag yang diuji berhasil terbaca oleh RFID reader dan kode serial yang tersimpan pada RFID yang berbeda-beda dapat ditampilkan di LCD.

\subsection{Pengujian Perangkat Lunak (Sofware)}

Secara umum pengujian perangkat lunak (software) bertujuan untuk mengetahui kinerja perangkat jika dikonfigurasikan dengan perangkat lunak yang sudah dibuat berdasarkan kebutuhan sistem sehingga dari pengujian perangkat lunak dapat diketahui sejauh mana perangkat dapat berkerja serta dapat mengetahui adanya eror yang didapat saat dilakukanya pengujian terhadap tampilan perangkat lunak yang sudah dibuat.

Pada pengujian perangkat lunak (sofware) perangkat rekam medis berbasis teknologi RFID dilakukan dua pengujian yakni pengujian komunikasi serial antara mikrokontrol Arduino Uno dengan sofware Visual Basic dan untuk pengujian yang ke dua yakni pengujian komunikasi serial antara sensor RFID reader, software Visual Basic dan kesesuian data yang diinputkan dengan database Microsoft Acces

4.2.1 Pengujian komunikasi serial mikrokontrol Arduino Uno dan RFID reader dengan software Visual Basic.

4.4 Data pengujian komunikasi serial mikrokontrol Arduino Uno dan RFID reader dengan software Visual Basic.

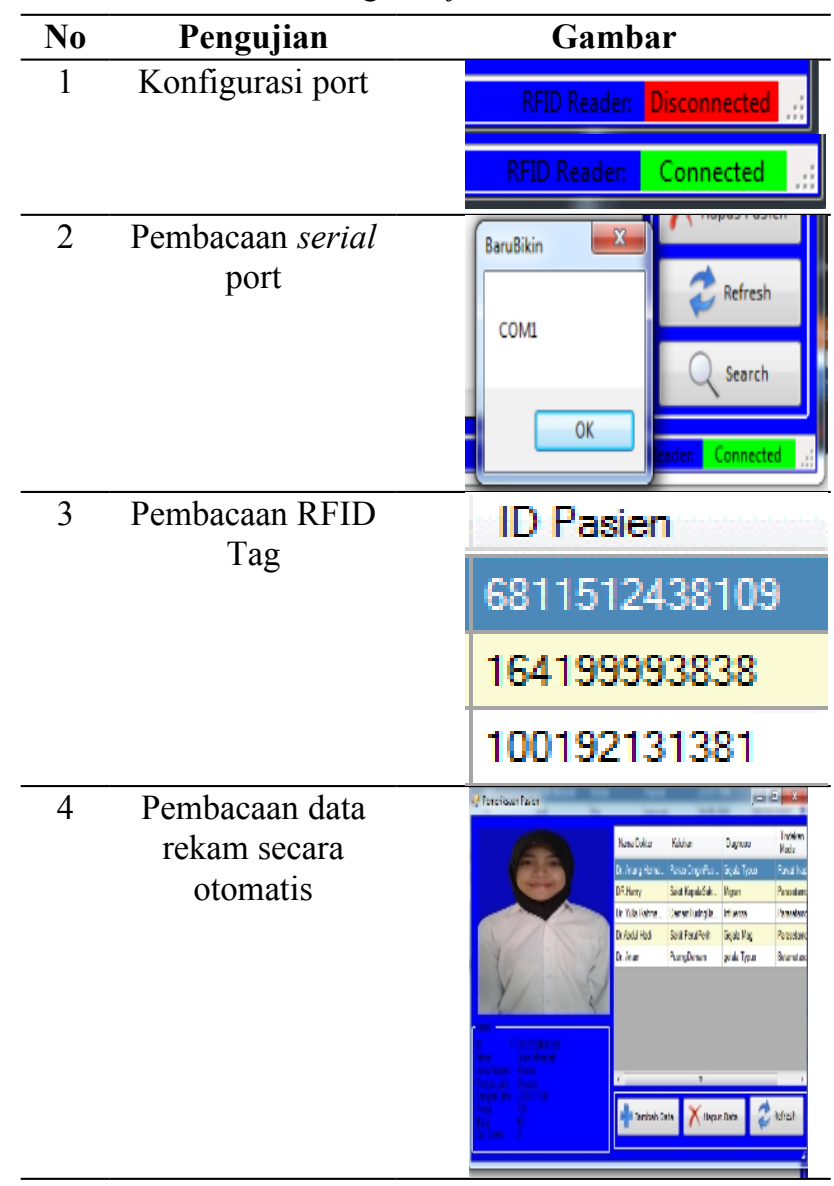

Pengujian komunikasi serial mikrokontrol Arduino Uno dan RFID reader dengan software Visual Basic beserta database software Microsoft Acces

4.5 Data pengujian komunikasi serial mikrokontrol Arduino Uno dan RFID reader dengan software Visual Basic. 


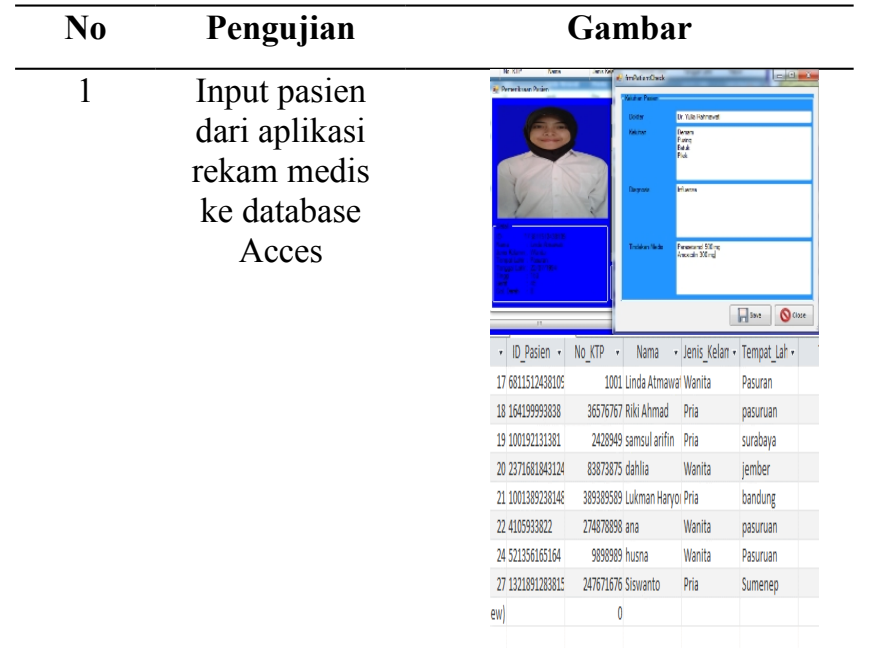

Pada pengujian dengan menggunakan tingkat kesesuaian informasi yang diinputkan dengan data yang tersimpan di database Acces apat dilihat pada tabel 4.6. Saat dilakukan pengujian dengan cara menginput data informasi pasien dan data rekam medik pasien pada aplikasi rekam medik yang sudah dibuat dengan menggunakan sofware Visual Basic. Data informasi yang diinputkan sudah berhasil tersimpan pada database Acces dan data yang tersimpan pada data base Acces sama dengan data yang sudah diinputkan oleh user dari aplikasi rekam medik yang dibuat pada sofware Visual Basic

Setelah dilakukan pengujian dengan menggunakan dua parameter berbeda yakni parameter yakni parameter input pasien dari aplikasi rekam medis ke database Acces dan parameter tingkat kesesuaian informasi yang di inputkan dengan data yang tersimpan di database Acces setelah dilakukan pengujian terhadap rancangan sistem aplikasi data rekam medik yang telah dibuat perangkat sudah dapat berjalan sesuai dengan rancangan sistem yang di harapkan Perbandingan Efisiensi Waktu Pelayanan Rekam Medik di UMC Dengan Alat Rekam Medik Berbasis Teknologi RFID

4.6 Data pengujian komunikasi serial mikrokontrol Arduino Uno dan RFID reader dengan software Visual Basic.

\begin{tabular}{cccc}
\hline No & Perbandingan & UMC & Perangkat \\
\hline 1 & Proses Registrasi & 3 Menit & 3 Menit \\
\hline 2 & $\begin{array}{c}\text { Proses Pencarian } \\
\text { data rekam medik }\end{array}$ & 2 Menit & 1.02 Menit \\
\hline 3 & $\begin{array}{c}\text { Proses Pemeriksaan } \\
\text { pasien }\end{array}$ & 4 Menit & 3 Menit \\
\hline 4 & $\begin{array}{c}\text { Proses Pelayanan } \\
\text { Rekam Medik } \\
\text { Secara Keseluruhan }\end{array}$ & 9 menit & 7.07 menit \\
\hline
\end{tabular}

Merupakan data perbandingan efisiensi waktu pelayanan rekam medik di UMC dengan rancangan alat rekam medik berbasis teknologi RFID yang telah di buat. Dalam proses pembandingan pelayanan data rekam medik yang ada di UMC dan pelayanan data rekam medik berbasis teknologi RFID menggunakan 4 parameter utama

Pada parameter pertama yakni perbandingan efisiensi waktu dalam proses registrasi pasien. Proses pelayanan registasi pasien yang ada di UMC rdan waktu yang di butuhkan dalam proses registrasi pasien dalam perangkat rekam medik berbasis teknologi RFID yang telah di buat sama yakni setiap pasienya berkisar 3 menit. Data tersebut di peroleh berdasarkan hasil survei lapangan dan berdasarkan data hasil pengujian perangkat rekam medik yang telah di buat.

Pada parameter kedua yakni perbandingan efisiensi waktu dalam proses pencarian data rekam medik pasien. Pada proses pencarian data rekam medik pasien yang ada di UMC rata-rata membutuhkan waktu selama 2 menit sedangkan proses pencarian dengan menggunakan perangkat rekam medik yang telah di buat membutuhkan waktu yang lebih singkat yakni 1.02 menit. Hal itu disebabkan proses pencarian data rekam medik pasien yang ada di UMC masih bergantung kecepatan petugas kesehatan yang melakukan pencarian data dengan cara mengetikan nama ataupun nomer rekam medik pasien secara manual 
pada personal komputer. Sedangkan proses pencarian data rekam medik pasien berbasis teknologi RFID yang telah di buat sudah menggunakan proses scaning otomatis menggunakan sensor RFID reader

Pada parameter tiga yakni perbandingan efisiensi waktu dalam proses Proses Pemeriksaan pasien. Pada proses Proses Pemeriksaan pasien yang ada di UMC rata-rata membutuhkan waktu selama 4 menit sedangkan proses pencarian dengan menggunakan perangkat rekam medik yang telah di buat membutuhkan waktu yang lebih singkat yakni 3 menit.

Pada parameter empat yakni perbandingan efisiensi waktu dalam proses pelayanan rekam medik secara keseluruhan. Pada proses pelayanan rekam medik secara keseluruhan yang ada di UMC rata-rata membutuhkan waktu selama 9 menit sedangkan proses pencarian dengan menggunakan perangkat rekam medik yang telah di buat membutuhkan waktu yang lebih singkat yakni 7.07 menit

Berdasarkan data perbandingan pelayanan rekam medik di UMC dan perangkat rekam medik berbasis teknologi RFID pada tabel 4.4 dapat di ketahui bahwa pada saat dilakukan pengujian terhadap proses pengambilan proses registrasi, proses pencarian data rekam medik, proses pemeriksaan pasien dan proses pelayanan rekam medik secara keseluruhan.

Pelayanan data rekam rekam medik berbasis teknologi RFID lebih efisien di bandingkan dengan pelayanan data rekam medik yang ada di UMC jika di kaji dalam segi waktu hal itu dapat di buktikan pada data pengujian pada tabel 4.4 dimana total waktu pelayanan data rekam medik di UMC secara keseluruhan yakni sebesar 9 menit sedangkan total waktu pelayanan data rekam medik berbasis teknologi secara keseluruhan 7,07 menit.

Adapun faktor-faktor yang mempengaruhi efisien waktu waktu pelayanan rekam medik yang ada di UMC dengan proses pelayanan rekam medik berbasis teknologi RFID di antaranya yaitu perbedaan tampilan aplikasi yang di buat, kelengkapan data rekam medik pasien yang di inputkan oleh dokter, dan dalam proses pencarian data rekam medik medik pasien di UMC masih menggunakan pencarian data nama pasien dan nomer rekam medik pasien dengan menggunakan pengetikan manual.

\section{KESIMPULAN}

Kesimpulan dari pengujian dan analisis data yang telah dilakukan adalah :

1. Proses pembacaan data rekam medik pasien secara otomatis dengan menggunakan perangkat rekam medik berbasis teknologi RFID dipengaruhi oleh posisi, sudut dan jarak penemptan tag terhadap sensor RFID reader, adapun posisi penempatan tag terbaik yakni tepat di depan sensor RFID reader dengan kisaran sudut $50^{\circ}-90^{0}$ dan jarak pembacaan maksimal sejauh $8 \mathrm{~cm}$ seperti pada tabel 4.1 halaman 30 .

2. Proses pelayanan rekam medik secara keseluruhan dengan perangkat rekam medik berbasis teknologi RFID lebih efisien 1.93 menit di bandingkan dengan proses pelayanan rekam medik di UMC, hal itu di sebabkan proses pencarian data rekam medik pasien dengan perangkat rekam medik berbasis teknologi RFID lebih cepat
1.02 dan proses pencarian data rekam medik di UMC serta dalam proses pemeriksaan pasien lebih cepat 1 menit di bandingkan proses pemeriksaan yang ada di UMC seperti data pada tabel 4.8 halaman 51 .

3. Proses pelayanan rekam medik dengan perangkat rekam medik berbasis teknologi RFID dapat mempermudah dokter dalam dalam menganalisa penyakit pasien karena dokter tidak perlu membutuhkan waktu lama dalam menganalisa penyakit pasien berdasarkan data rekam medik pasien yang telah lalu dapat dilihat dengan mudah melalui hasil scaning otomatis data rekam medik pasien dengan sensor RFID reader.

\section{SARAN}

Beberapa saran yang dapat dipertimbangkan untuk pengembangan penelitian selanjutnya adalah:

1. Perlu adanya pengembangan perangkat rekam medik berbasis teknologi RFID dengan menggunakan database online berbasisi pemogramam SQL dan PHP

2. Perlu adanya pengembangan tentang menu tampilan utama aplikasi rekam medik berbasis teknologi RFID agar terlihat lebih menarik dan informasi data rekam medik yang di tampilkan lebih lengkap.

\section{DAFTAR PUSTAKA}

[1] Muis, M. Kom, Dr. Ir. Saludin. 2013. "Prinsip Kerja LCD Dan Pembuatannya (Liquid Crystal Display)“. Yogyakarta: Graha Ilmu.

[2] Artanto, Dian. 2012. "Interaksi Arduino dan Labview”. Jakarta: Elex media. Komputindo.

[3] Adam, Wahyu, M.Eng.Sc dan Lamhot Sagala. 2014. Jurnal Sistem Absensi Pegawai Menggunakan Teknologi RFID. Bandung.

[4] Setiawan, Yasin, S.Kom dan Evi Susanti, S.Si. 2013. Jurnal Perancangan Modul Security Pemustakan (Check-in) Sirkulasi Perpustakaan Universitas Riau. Riau.

[5] Bhakti, Dinar W, dkk. 2012. Jurnal Rancang Bangun Mesin Kehadiran Dengan Menggunakan Kode Bar. Lampung.

[6] http://library.unej.ac.id/client/en US/default/search/ results?qu $=r f i d \& i c=$ true $\&$ te $=\& p s=300$. [Diakses 10 Januari 2015].

[7] https://id.wikipedia.org/wiki/Berkas:Batteries.jpg. [Diakses 13 Januari 2015].

[8] http://elektronika-dasar.web.id/lcd-liquid-cristaldisplay/. [Diakses 13 Januari 2016].

[9] http://teknikelektronika.com. [Diakses 13 Januari 2016].

[10] http://www.prinsipkerjarfid.com/peralatan/prinsipkerja-baterail. [Diakses 13 Januari 2016].

[11] http://teknikelektronika.com/pengertian-saklar-listrikcara-kerjanyal. [Diakses 13 Januari 2016]. 